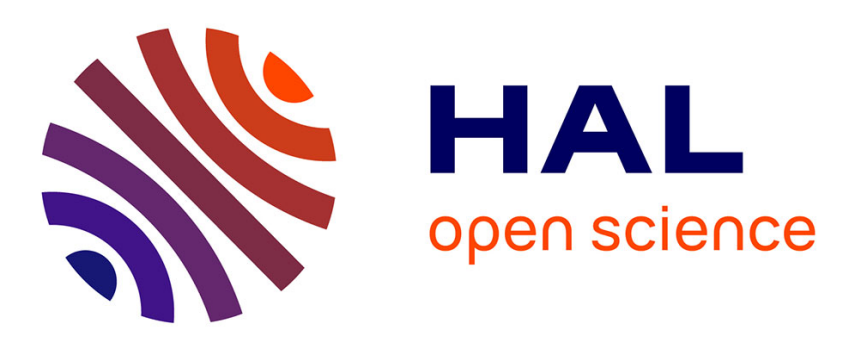

\title{
A simple model of flow-rate attenuation in sewer systems. Application to urban stormwater source control Guido Petrucci, Bruno Tassin
}

\section{To cite this version:}

Guido Petrucci, Bruno Tassin. A simple model of flow-rate attenuation in sewer systems. Application to urban stormwater source control. Journal of Hydrology, 2015, 522, pp.534-543. 10.1016/j.jhydrol.2015.01.012 . hal-01136837

\section{HAL Id: hal-01136837 \\ https://hal-enpc.archives-ouvertes.fr/hal-01136837}

Submitted on 30 Mar 2015

HAL is a multi-disciplinary open access archive for the deposit and dissemination of scientific research documents, whether they are published or not. The documents may come from teaching and research institutions in France or abroad, or from public or private research centers.
L'archive ouverte pluridisciplinaire HAL, est destinée au dépôt et à la diffusion de documents scientifiques de niveau recherche, publiés ou non, émanant des établissements d'enseignement et de recherche français ou étrangers, des laboratoires publics ou privés. 


\title{
A simple model of flow-rate attenuation in sewer systems. Application to urban stormwater source control.
}

\author{
Guido Petrucci ${ }^{\mathrm{a}, *}$, Bruno Tassin ${ }^{\mathrm{b}}$ \\ ${ }^{a}$ Earth System Sciences (ESSC), Vrije Universiteit Brussel, Pleinlaan, 2 - 1050 Brussels - Belgium \\ ${ }^{b}$ Université Paris-Est. Laboratoire Environnement Eau Systèmes Urbains (UMR MA102), UPEC, UPEMLV, ENPC, AgroParisTech. 6-8 avenue \\ Blaise Pascal, 77455 Champs sur Marne cedex 2, France
}

\begin{abstract}
In urban stormwater management, "soft" solutions are being widely applied, including stormwater source control. However, no specific resource-effective model is available to assess their effects at the city-scale. As a consequence, source control regulations are often based on simplistic hydrologic assumptions. In this paper, we apply a top-down modeling approach to this problem, and we develop a simple model of flow-rate attenuation in the sewer system, using a numerical empirical approach. Then, we apply the model to source control regulations, assessing which type of regulation is more effective depending on relative positions in a catchment. We show that a model requiring only two types of information about a catchment (concentration time and pluviometry) can provide relevant information on source control effectiveness. This information could be helpful, for example, to define a stormwater zoning.
\end{abstract}

Keywords: urban hydrology, storm drainage, source control, top-down modeling, best management practices, flow attenuation

\section{Introduction}

Stormwater management in urban areas is a topic of growing complexity. Besides the increasing size and vulnerability of the urban systems themselves, which makes it more difficult to protect people and assets from flooding, new objectives are set for stormwater management in terms of protection of receiving water bodies and resource preservation. New strategies have been elaborated in the last decades, including RealTime Control (RTC) of drainage systems, radar-based rainfall predictions, small-scale storage/infiltration facilities distributed all over a catchment (source control). The Novatech international conferences, which arrived at their 8th edition in 2013, show the evolutions of these new strategies.

Some of these strategies brought to the development and use by local authorities of advanced management and simulation models at the city scale. For example, RTC is generally associated with detailed models of sewer systems, allowing the optimization of the system's operation (Schütze et al. 2004, Labadie, 2007).

\footnotetext{
${ }^{*}$ Corresponding author

Email addresses: guido.petrucci@vub . ac. be (Guido Petrucci), bruno.tassin@enpc.fr (Bruno Tassin)
}

However, other new strategies (in a general way, those involving "soft" infrastructures) did not produce specific modeling solutions at the catchment-scale.

Stormwater source control is a good example: this strategy consists of the implementation of stormwater management facilities (often called Best Management Practices, BMPs) like storage ponds, green roofs and porous pavements (Azzout et al. 1994, Revitt et al., 2008) at the scale of urban parcels or housing estates. The purpose is to mimic to some extent the behavior of the catchment before urbanization (Booth and Jackson, 1997; Andoh and Declerck, 1999; Walsh et al., 2005). The main instruments for local authorities to develop source control are regulations prescribing BMPs in all new urban developments or renovations (e.g. Balascio and Lucas (2009)). Source control regulations set the limit between the spatially-distributed, private management of stormwater on one side and the traditional, centralized public drainage system on the other. A proper decision-making procedure, coupling source control to other strategies of stormwater management, would be required to set this limit together with the optimization of RTC or of the other strategies applied. This procedure, requiring specific modeling tools, would allow "source control optimization" as part of a wider 
stormwater management optimization.

Research mainly focused on French case studies (Petrucci et al., 2013) showed that source control regulations, despite their wide use, are generally a compromise between strongly simplified technical considerations and pragmatical considerations of applicability. Local authorities in charge of large and complex sewer systems often have a detailed model of them, developed to support management and, in some cases, RTC. The models currently used are, for example, SWMM, Infoworks, MIKE, CANOE. Although these models can be used, in principle, to find effective source control regulations (Mouy et al., 2007), their application to this purpose is often limited. For example, it is a current practice to use models to determine the maximum acceptable discharge at "bottlenecks" in the sewers. This maximum discharge, divided by the upstream area, is then used as the regulation value and applied to every parcel (Petrucci et al., 2013). Furthermore, the adoption of source control regulations extends today to an increasing number of local authorities that do not have an already available model of their sewer system. Where no model is available, its complexity and cost (involving the modeling itself, but also data collection and upkeeping) discourage authorities from developing one.

As a consequence, many regulations are biased by conceptual shortcuts. For example, most regulations are fixed on the basis of a "the more the better axiom", assuming that a more strict regulation (i.e. prescribing to manage more water at the parcel level) is always more beneficial than a less strict one. This assumption goes to the extreme of regulations that prescribe to manage all the water at the parcel level (Urbonas and Jones 2001), disregarding efficiency and potential negative effects of excessive constraints (Petrucci et al., 2013). Another recurrent shortcut is to fix regulations on a uniform basis over large catchments (i.e. in the form of a unique constraint for all new developments), neglecting geographical and topographical specificities, differences between upstream and downstream areas, and any other structural or hydrologic heterogeneity (Faulkner 1999). More generally, the aggregation of the flow-rate contributions from the individual small-scale BMPs to the city-scale is usually realized as a linear composition, disregarding all the flow processes occurring in the drainage system, like the superposition and propagation of contributions, backwater effects, overflows, etc.

The way to a more effective inclusion of "soft" infrastructures in stormwater management at the city scale includes, as a necessary but probably not sufficient condition (Roy et al. 2008), the development of models having two characteristics:
- they should be able to describe the more significant processes at the right scale and for the strategy studied. These processes are not necessarily the same described by traditional sewer system models.

- they should be "efficient" (or at least "reasonable") in terms of data requirements: to study a city-scale long-term regulation, it should not be required to describe each existing or planned gutter or sidewalk.

A promising way to develop similar models is to adopt a top-down reasoning. A top-down (or downward) approach in hydrologic modeling means to "start with trying to find a distinct conceptual node directly at the level of interest (or higher) and then look for the steps that could have led to it from a lower level" (Klemeš, 1983). By contrast, the bottom-up (or upward, or reductionist) approach describes the behavior of a hydrologic system at a given scale as the aggregation of processes at lower scales. Most models, if not all, used today in urban hydrology (Elliott and Trowsdale 2007) follow this last paradigm, describing the catchment as a combination of elementary components (sub-catchments or grid meshes). The scientific debate about this opposition is long-lasting and rich (after Klemeš (1983), for instance, Blöschl and Sivapalan (1995); Bergstrom and Graham (1998); Andréassian (2005); Sivapalan and Young (2005)). The main argument of the promoters of the top-down approach is epistemological: a complex system has emerging properties that cannot be inferred by the properties of its components (Andréassian, 2005). A bottom-up approach is unable to catch these properties, while a top-down can.

From the authors' point of view, the top-down approach has another, more operational, advantage. Bottom-up models require a detailed description of a catchment to analyze its large-scale behavior, thus requiring large quantities of data to answer large-scale questions (e.g. Lee et al., 2012). Conversely, a topdown approach can provide "data-parsimonious" models, by trying to answer a large-scale question at the scale where it is asked, using only the strictly necessary data. This data-parsimony can be a significant advantage in terms of applicability of the model by local authorities, as it can reduce modeling costs.

The purpose of this paper is to illustrate the potential of top-down modeling in urban hydrology: starting from a process that is relevant at the city-scale level, but usually neglected in policy-making about source control regulations (i.e. flow-rate attenuation in the drainage system), we build a simple, data-parsimonious model. 
Then, we test its implications for the development of source control regulations that are more consistent at the city-scale.

\subsection{Flow-rate attenuation in pipes and its impact on source control}

A hydrograph measured upstream and downstream of a pipe or of a series of pipes is not just translated, but it incurs a deformation and, in particular, its maximum flow-rate is attenuated (Kovacs (1988); figure 1). In the absence of backwater effects, the shape of the hydrograph at the outlet will depend on its shape at the inlet and on the characteristics of the pipes where it flows through. In terms of source control regulations, this implies that identical hydrographs entering the drainage system at different points will contribute differently to the cumulative hydrograph at the outlet of the drainage system. Intuitively, the longer the path of the hydrograph in the sewer, the greater its deformation, and the more attenuated its peak flow-rate. Thus, a new urban development far from the outlet will produce, in terms of peak flow-rate at the sewer's outlet, a smaller contribution than the one of an identical urban development closer to the outlet. Today, in many urban areas, new developments occur upstream of existing settlements, with paths in the sewer system reaching easily lengths of several kilometers. This article aims to analyze if, in conditions representative of actual urban areas and sewer systems, the effect of the attenuation process on the performances of source control regulations is significant.

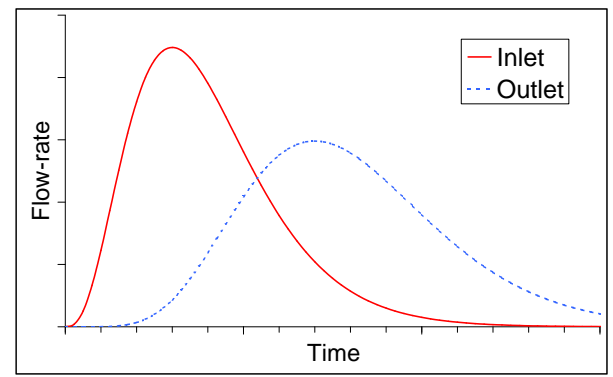

Figure 1: Deformation of a hydrograph flowing in a pipe after Kovacs (1988)

With this objective, this paper is structured in two parts: the first is the development of a simple model of peak flow-rate attenuation in pipes (the attenuation model), based on numerical experiments on a mechanistic model of flow in pipes (the flow model); the sec- ond is the application of the attenuation model to source control regulations.

\section{Part I: model development}

\subsection{Methodology}

\subsubsection{Overview: flow-rate attenuation in pipes and its assessment}

Peak attenuation is a process widely addressed in hydraulics and hydrology, mainly for the study of peak flow-rates propagation in river flooding (see, for instance, Chow (1959) and Hingray et al. (2009)). The current approach in the fluvial domain, when detailed models are not available, is to consider a simplified version of the de Saint-Venant equations (Weinmann and Laurenson, 1979), and to apply it to the flood-wave propagation.

Conversely, except for some detailed engineering applications, studies on attenuation in sewer systems are uncommon. Kovacs (1988) analyzed the applicability of different simplified versions of de Saint Venant equations, and the main factors affecting attenuation. He could not distinguish clearly, in usual sewer system conditions, whether attenuation is relevant or not.

In theory, it is possible to study attenuation in sewers starting from the de Saint-Venant equations and their simplifications. In particular, a "diffusion coefficient" is present in the diffusive wave model, and it influences the hydrograph widening and attenuation (Viollet et al., 2002). However, these models do not have, in general, an analytical solution. Thus, to know the shape (or just the peak flow-rate) of a hydrograph at the outlet of a pipe or sewer, it is necessary to integrate the equations for each given hydrograph at an inlet. In some cases it is possible to consider the coefficients of the diffusive wave model as constants, as used in the Hayami model, successfully used for river flood simulations (Hayami, 1951; Chow, 1959, Kovacs, 1988). However, flow-rates entering sewers can have fast variations, particularly during strong rain events, and the Hayami model is not applicable.

A different approach to study peak flow-rate attenuation in sewers has been tested, when computer facilities were limited, in order to develop a pipe dimensioning method accounting for this process (Ackers and Harrison, 1964, Ackers et al., 1965). The approach of Ackers and Harrison was not based on mechanistic models resulting from de Saint-Venant equations, but on a physical model. They performed a series of experiments on a pipe physical model, observing the evolution of the 
peak height of hydrographs superposed on a permanent flow.

Our purpose in this research is close to that of Ackers and Harrison: we create a model of attenuation linking the peak flow-rate of a hydrograph entering a pipe to the corresponding peak flow-rate at the outlet, without performing simulations for each hydrograph. In Petrucci and Tassin (2011), we presented an introductory analysis based on the results of Ackers et al. (1965). Even if this approach provides some observations on source control regulations, it is not satisfactory for two reasons. First, although Ackers and Harrison could test the influence of some parameters on attenuation, their experimental setting does not allow the assessment of other important factors like pipe diameters. Second, their analysis was focused on the hydrograph peaks' height relative to the pipe diameter; if this choice was acceptable for sewer dimensioning, it is not for source control considerations. In fact, because of the variety of BMPs and of their design, it is impossible to define a standard reference equivalent to pipe diameter. Thus, the concept of relative height is ambiguous in terms of source control, and an analysis of flow-rates is more pertinent.

To obtain a model of attenuation expressed in terms of flow-rates, we have used a numerical experimental approach. Following the procedure of Ackers and Harrison (1964), we performed experiments on the model of a pipe under different flow conditions. Starting from the experiments' results, we searched for an empirical equation linking peak flow-rates at the inlet and at the outlet of a pipe with hydrograph's and pipe's characteristics. The difference from the procedure followed in the cited work is that we used a numerical model of pipes for experiments, instead of a physical one.

\subsubsection{Experimental setting}

We consider a circular pipe of diameter $D$, length $l$, slope $s$, Manning's coefficient $n$. Full-section velocity is calculated by the Manning-Strickler formula (Hingray et al. 2009), as a function of the hydraulic radius $R_{h}$ :

$$
v_{f}=\frac{1}{n} R_{h}^{2 / 3} s^{1 / 2} ; R_{h}=\frac{D}{4}
$$

At full section, flow-rate is $Q_{f}=v_{f} \cdot \frac{\pi D^{2}}{4}$. We can define, following Ackers and Harrison (1964), a dimensionless number $F_{f}=v_{f} \cdot(g \cdot D)^{-\frac{1}{2}}$, having a formulation similar to the Froude number. The pipe's volume is $V_{c}=\frac{\pi D^{2}}{4} l$. Values of pipe's characteristics can vary in ranges determined by current practices in sewer systems dimensioning (Chocat et al., 1997; Rossman, 2004), as defined in table 1

\begin{tabular}{lccc} 
Symbol & Units & Min & Max \\
\hline$l$ & $\mathrm{~m}$ & 50 & 3000 \\
$D$ & $\mathrm{~m}$ & 0.5 & 3 \\
$s$ & $\mathrm{~m} / \mathrm{m}$ & 0.004 & 0.05 \\
$n$ & $\mathrm{~m}^{-1 / 3} \mathrm{~s}$ & 0.01 & 0.017 \\
$v_{f}$ & $\mathrm{~m} / \mathrm{s}$ & 0.75 & 6
\end{tabular}

Table 1: Ranges of pipe's characteristics.

Inside the pipe, we consider a uniform flow-rate $Q_{0}$ representing the base flow (dry weather flow, etc.). To this uniform flow-rate is superposed a semisinusoidal hydrograph (according to a suggestion of Ko$\operatorname{vacs}(1988)$ ) of duration $d$, peak flow-rate $Q_{i n}$ and volume $V$ (figure 2). For this hydrograph shape, the relationship between these three characteristics can be written:

$$
V=\alpha \cdot Q_{\text {in }} \cdot d, \text { with } \alpha=\frac{2}{\pi}
$$

In validation (AppendixA), we consider different hydrograph shapes, leading to different values of $\alpha(0.5<$ $\alpha<1)$.

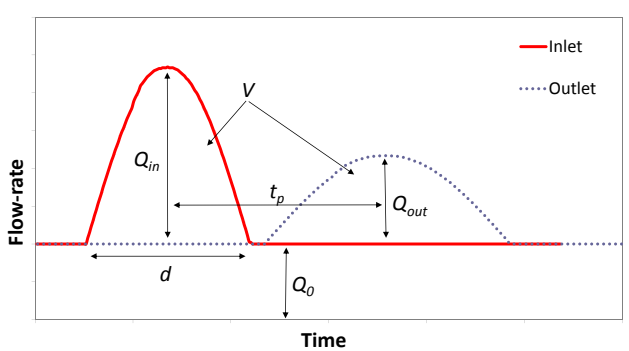

Figure 2: Characteristics of the hydrographs inside the pipe

\subsection{3. dimensionless factors and tested equations}

Our purpose is to find a function expressing the $Q_{\text {out }} / Q_{\text {in }}$ ratio depending on variables describing the pipe and the hydrograph at the inlet. As suggested by Ackers and Harrison (1964), we group the variables in a set of dimensionless numbers, supposed to be explanatory of the attenuation process. We considered three numbers suggested by these authors, and a fourth one based on the work of Kovacs. 
- $X_{1}=\frac{V_{c}}{V \cdot F_{f}}$. This dimensionless number groups the ratio between pipe's and hydrograph's volume and the $F_{f}$ variable. It was the main explanatory factor as determined by Ackers and Harrison (1964).

- $X_{2}=\frac{Q_{0}}{Q_{f}}$. This number describes the initial filling of the pipe.

- $X_{3}=\frac{Q_{i n}}{Q_{f}}$. This number takes into account the peak flow-rate at the inlet.

- $X_{4}=\frac{V_{c}}{V} \cdot \frac{Q_{i n}}{Q_{f}}$. This last number is an approximation of the ratio $\frac{t_{p}}{d}$, between the travel-time in the pipe $t_{p}$ and the hydrograph duration $d$. In fact, if we consider the full-section velocity as reference, $t_{p}=\frac{l}{v_{f}}$. Thus, considering eq. 2 ,

$$
\frac{t_{p}}{d}=\frac{l}{v_{f}} \cdot \frac{\alpha Q_{i n}}{V}
$$

Multiplying and dividing by the pipe's section $S=$ $\frac{\pi D^{2}}{4}$,

$$
\frac{t_{p}}{d}=\frac{(S \cdot l)}{\left(S \cdot v_{f}\right)} \cdot \frac{\alpha Q_{i n}}{V}=\frac{V_{c}}{Q_{f}} \cdot \frac{\alpha Q_{i n}}{V}
$$

Thus,

$$
\frac{t_{p}}{d}=\alpha \frac{V_{c}}{V} \cdot \frac{Q_{i n}}{Q_{f}} \propto X_{4}
$$

The relevance of the hydrograph's shape factor $\alpha$ is discussed in AppendixA

Using these four numbers, we search an equation expressing:

$$
\frac{Q_{\text {out }}}{Q_{\text {in }}}=f\left(X_{1}, \ldots, X_{4}\right)
$$

We test three formulations for the attenuation model, depending on the sets of parameters $a_{i}$ and $b_{i}$ :

$$
\begin{aligned}
\frac{Q_{\text {out }}}{Q_{\text {in }}} & =a \prod_{i=1}^{4} X_{i}^{b_{i}} \\
\frac{Q_{\text {out }}}{Q_{\text {in }}} & =a_{0}+\sum_{i=1}^{4} a_{i} X_{i}^{b_{i}} \\
\frac{Q_{\text {out }}}{Q_{\text {in }}} & =\left(a_{0}+\sum_{i=1,3,4} a_{i} X_{i}\right)^{b+a_{2} X_{2}}
\end{aligned}
$$

Equations 4 and 5, that we call multiplicative and additive models, are simple attempts of model fitting. Equation 6 is inspired by the formulation proposed by Ackers et al. (1965) and used in Petrucci and Tassin (2011), and is addressed as the Ackers model.

\subsubsection{Simulations and model fitting}

We realized $N=10,000$ simulations of one hydrograph flowing through a single pipe. For each one, we considered a randomly generated pipe and hydrograph using the ranges presented in table 1 The simulations were performed using the model SWMM 5; this code integrates the complete de Saint Venant equations using an explicit finite differences method (Rossman and Supply, 2006). Details on the extraction and simulation procedure are given in AppendixB

Then, we adjusted the parameters of eq. 4 to 6 in order to fit the attenuation model to the simulations' outcome. We call $y_{n}=\frac{Q_{\text {out }}}{Q_{i n}}$ the attenuation obtained at the $n$-th simulation, and $\hat{y}_{n}=f(X, a, b)$ the corresponding value as estimated by one of the three models. We fitted each model by minimizing the mean square error:

$$
\min _{a, b} M S E=\min _{a, b}\left[\frac{1}{N} \sum_{n=1}^{N}\left(y_{n}-\hat{y}_{n}\right)^{2}\right]
$$

For a better interpretation of results, we also calculated the coefficient of determination $R^{2}$ :

$$
R^{2}=1-\frac{\sum_{n=1}^{N}\left(y_{n}-\hat{y}_{n}\right)^{2}}{\sum_{n=1}^{N} y_{n}^{2}}
$$

This coefficient varies between 0 and 1 ; the closer it is to the unity, the better the estimations fit the observations.

Moreover, to assess whether the model incurs any systematic errors, we calculated the residuals' firstorder autocorrelation, after ordering the observations:

$r_{c}=\frac{\sum_{n=1}^{N-1}\left[\left(\epsilon_{n}-\bar{\epsilon}\right)\left(\epsilon_{n-1}-\bar{\epsilon}\right)\right]}{\sum_{n=1}^{N}\left(\epsilon_{n}-\bar{\epsilon}\right)} ; \bar{\epsilon}=\frac{1}{N} \sum_{n=1}^{N} \epsilon_{n} ; \epsilon_{n}=y_{n}-\hat{y}_{n}$

$r_{c}$ ranges between 0 and 1 . A value close to 0 is preferable, meaning that residuals are not autocorrelated.

\subsection{Results and discussion}

Figures 3,4 and 5 present the results of the model fitting for, respectively, the multiplicative, additive and Ackers models.

From both the plots and the values of $M S E$ and $R^{2}$, it is evident that the multiplicative model underperforms compared to the two others. For this reason, we will exclude it from the following analyses.

The additive model, on the contrary, is well performing $\left(M S E=4.70 \times 10^{-4}, R^{2}=0.951\right)$. To analyze the relative weight of each dimensionless factor in the model, table 2 presents a variability analysis of the terms $a_{i} X_{i}^{b_{i}}$, for the $N$ simulations. The most significant 


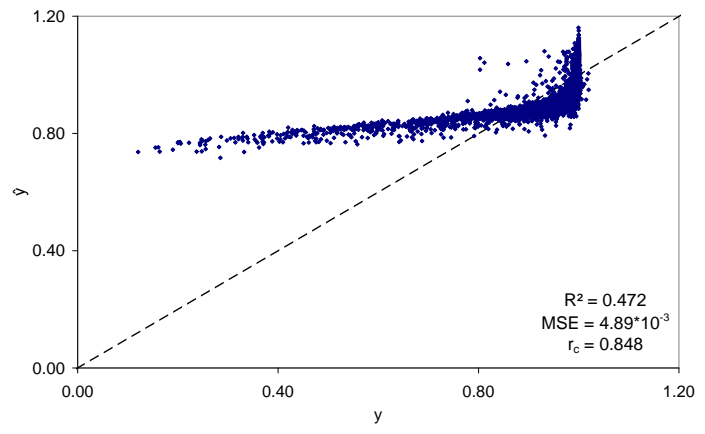

Figure 3: Best fit of the multiplicative model (eq. 4).

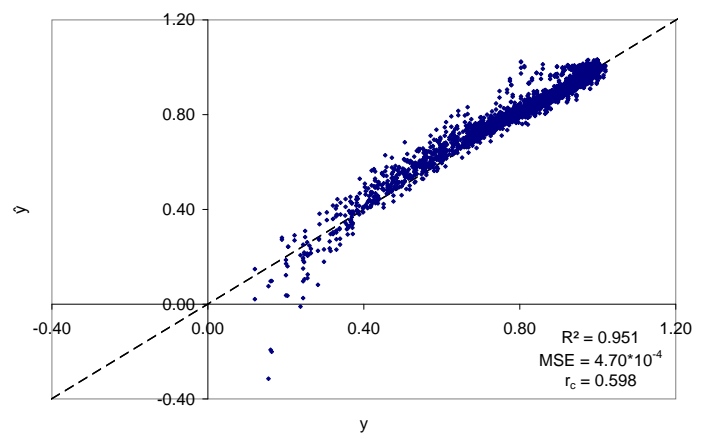

Figure 4: Best fit of the additive model (eq. 5).

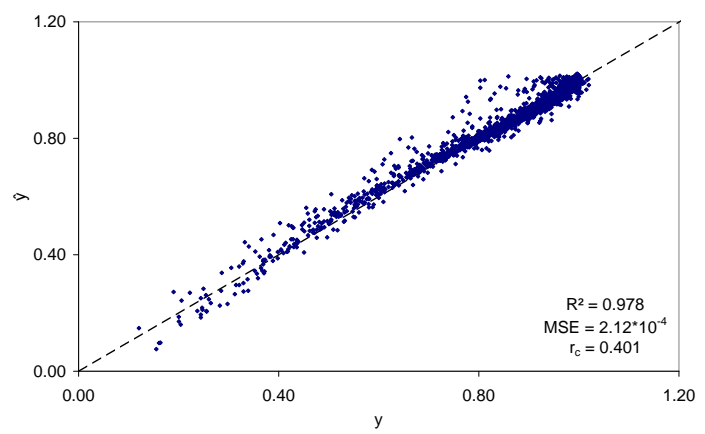

Figure 5: Best fit of the Ackers model (eq. 6). term is that depending on $X_{4}=\frac{V_{c} \cdot Q_{i n}}{V \cdot Q_{f}}$. This fact suggests that we should test a simplified additive model:

$$
\frac{Q_{\text {out }}}{Q_{\text {in }}}=a_{0}+a_{4} X_{4}^{b_{4}}
$$

The result of this model's fitting is presented in figure 6 . $M S E$ is obviously larger than for the complete additive model, but of the same order of magnitude; $R^{2}$ is still higher than 0.9.

Overall, the two additive models show similar behaviors, with a strong dispersion for high attenuation values $(y<0.4)$. For really high values, $\hat{y}$ can be negative. Both models have a systematic bias (witnessed by a significant value of $r_{c}$ ), overestimating attenuation for intermediate cases $(0.4<y<0.8)$; this bias is stronger for the simplified model. However, the two models show good performance in terms of $R^{2}$, and they provide estimations that should be satisfactory for most applications. In particular, the simplified additive model has the practical advantage of linking attenuation to a single factor.

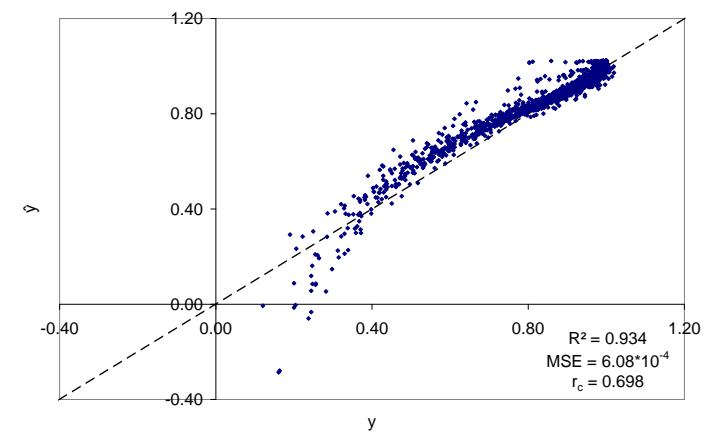

Figure 6: Best fit of the simplified additive model (eq. 10 .

The Ackers model performs slightly better than the additive one $\left(M S E=2.12 \times 10^{-4}, R^{2}=0.977\right)$. Further, (i) it does not provide negative predictions and (ii) systematic bias for intermediate values of attenuation is less marked $\left(r_{c}=0.401\right)$. It is possible, in analogy with the additive model, to define a simplified Ackers model:

$$
\frac{Q_{\text {out }}}{Q_{\text {in }}}=\left(a_{0}+a_{4} X_{4}\right)^{b+a_{2} X_{2}}
$$

This model, once fitted, gives the results presented in figure 7. Also in this case, the worsening of the performances with simplification is small $(M S E=$ $\left.3.30 \times 10^{-4}, r^{2}=0.965\right)$, but there is an increment of the bias for intermediate attenuation $\left(r_{c}=0.637\right)$.

To summarize, the four models discussed are presented in table 3 , ordered by MSE. All these models 


\begin{tabular}{r|rrrr} 
& $a_{1} X_{1}^{b_{1}}$ & $a_{2} X_{2}^{b_{2}}$ & $a_{3} X_{3}^{b_{3}}$ & $a_{4} X_{4}^{b_{4}}$ \\
\hline quantile 0.05 & 2.02 & 0.07 & 0.15 & -0.30 \\
quantile 0.95 & 2.09 & 0.08 & 0.22 & -0.02 \\
$\left|\left(q_{0.95}-q_{0.05}\right) / a_{0}\right|$ & $6 \%$ & $1 \%$ & $6 \%$ & $23 \%$
\end{tabular}

Table 2: Variability factors for the additive model $\left(N=10,000, a_{0}=-1.24\right)$.

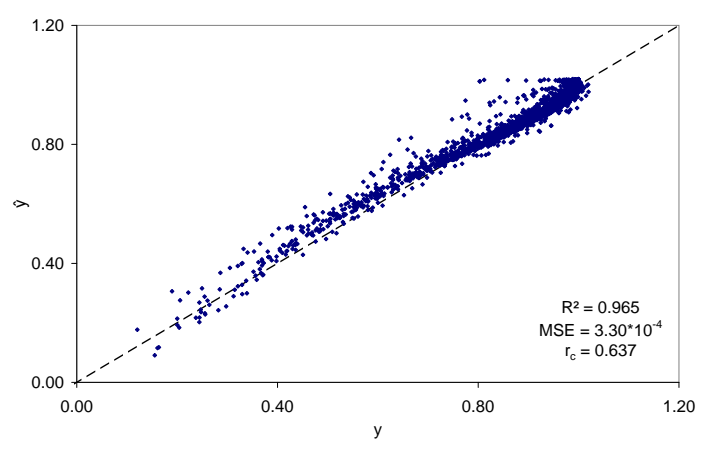

Figure 7: Best fit of the simplified Ackers model (eq. 11.

have similar performances, at least in terms of $M S E$ and $R^{2}$. This fact suggests that the choice between one model or the other will depend on the expected application. In the next part of this article, for instance, we develop a reasoning on source control which is not focused on a specific urban area and sewer system. For this general purpose we will use the simplest of the models (simplified additive).

\section{Part II: application to source control}

The purpose of this part is twofold: firstly, it aims to define the extent to which attenuation is a relevant process in ordinary stormwater sewer system conditions; secondly, it aims to characterize the impact of this process on source control regulations. Thus, we will consider two cases using one of the models obtained in the preceding part.

The first case is a sewer system receiving runoff from a critical rain event, defined as the event whose intense duration $d_{\text {rain }}$ is close to the catchment concentration time $t_{c}$. This represents typical dimensioning conditions for sewer systems.

The second case is that of source control regulations: we will consider different types of regulation applied at variable distances from the outlet and analyze how flow-rate attenuation affects their effectiveness in reducing the peak flow-rate at the outlet.

\subsection{Flow-rate attenuation in a sewer system under a critical rain event}

It is possible to reformulate the simplified additive model:

$$
{\frac{Q_{\text {out }}}{Q_{\text {in }}}}=1.02-0.190{\frac{V_{c} \cdot Q_{\text {in }}}{V \cdot Q_{f}}}^{0.786}=1.02-0.190 t_{p} \cdot{\frac{Q_{\text {in }}}{V}}^{0.786}
$$

and, using Equation 3 to approximate it (see AppendixA for a discussion of this approximation)

$$
\frac{Q_{\text {out }}}{Q_{\text {in }}}=1.02-0.190{\frac{V_{c} \cdot Q_{\text {in }}}{V \cdot Q_{f}}}^{0.786} \approx 1.02-0.190{\frac{t_{p}}{d}}^{0.786}
$$

Thus, it is possible to study attenuation as a function of the two variables $t_{p}$ and $d$ (figure 8). The figure shows that attenuation is small for $d>t_{p}$. For the line $d=t_{p}$, $\frac{Q_{\text {out }}}{Q_{\text {in }}} \approx 0.83$. Conversely, for hydrographs having a duration shorter than their travel time in the sewer, attenuation can become significant. In the usual conditions of stormwater sewer systems, which of the two cases is most likely to be verified?

Consider a catchment with a concentration time $t_{c}$. Under the hypothesis that the time of surface runoff is small compared to the flow in the sewer system (which is often the case in urban settings, Chocat et al. (1997)), the travel time in the sewer system between the farthest impervious areas of the catchment and the outlet will be similar to $t_{c}$. For hydrographs generated by these impervious areas, then, $t_{p} \approx t_{c}$.

An empirical rule widely applied in urban hydrology is to consider that the rainfall events producing the largest flow-rate at the outfall of a catchment are the events having a duration $d_{\text {rain }}$ close to the concentration time of the catchment $\left(t_{c} \approx d_{\text {rain }}\right)$. We can also consider that, for a small impervious surface, the duration of a hydrograph entering the sewer is close to the duration of the rainfall generating it $\left(d_{\text {rain }} \approx d\right)$.

Under these hypotheses, we deduce that attenuation will not be relevant for the study of critical rainfall and flow-rates on urban catchments under "standard" conditions: even for the farthest impervious areas in a catchment, $t_{p}$ is of the same order than $d\left(t_{p} \approx d\right)$, and the maximum attenuation in the catchment will be around $20 \%$. 


\begin{tabular}{|c|c|c|c|c|}
\hline Modèle & $\begin{array}{l}M S E \\
\left(\cdot 10^{-4}\right)\end{array}$ & $R^{2}$ & $r_{c}$ & $\frac{Q_{\text {out }}}{Q_{\text {in }}}=$ \\
\hline Ack. comp. & 2.12 & 0.978 & 0.401 & $\left(0.996+9.88 \times 10^{-4} \frac{V_{c}}{V \cdot F_{f}}-1.21 \times 10^{-2} \frac{Q_{i n}}{Q_{f}}+5.54 \times 10^{-2} \frac{V_{c} \cdot Q_{i n}}{V \cdot Q_{f}}\right)^{-5+1.60 \frac{Q_{0}}{Q_{f}}}$ \\
\hline Ack. simp. & 3.30 & 0.965 & 0.637 & $\left(0.996+4.89 \times 10^{-2} \frac{V_{c} \cdot Q_{i n}}{V \cdot Q_{f}}\right)^{-5+1.20 \frac{Q_{0}}{Q_{f}}}$ \\
\hline Add. comp. & 4.70 & 0.951 & 0.598 & $-1.24+2.06{\frac{V_{c}}{V \cdot F_{f}}}^{9.53 \times 10^{-3}}+7.71 \times 10^{-2}{\frac{Q_{0}}{Q_{f}}}^{3.41 \times 10^{-2}}+0.232{\frac{Q_{i n}}{Q_{f}}}^{0.137}-0.280{\frac{V_{c} \cdot Q_{i n}}{V \cdot Q_{f}}}^{0.647}$ \\
\hline Add. simp. & 6.08 & 0.934 & 0.698 & $1.02-0.190{\frac{V_{c} \cdot Q_{i n}}{V \cdot Q_{f}}}^{0.786}$ \\
\hline
\end{tabular}

Table 3: Summary of the attenuation models.

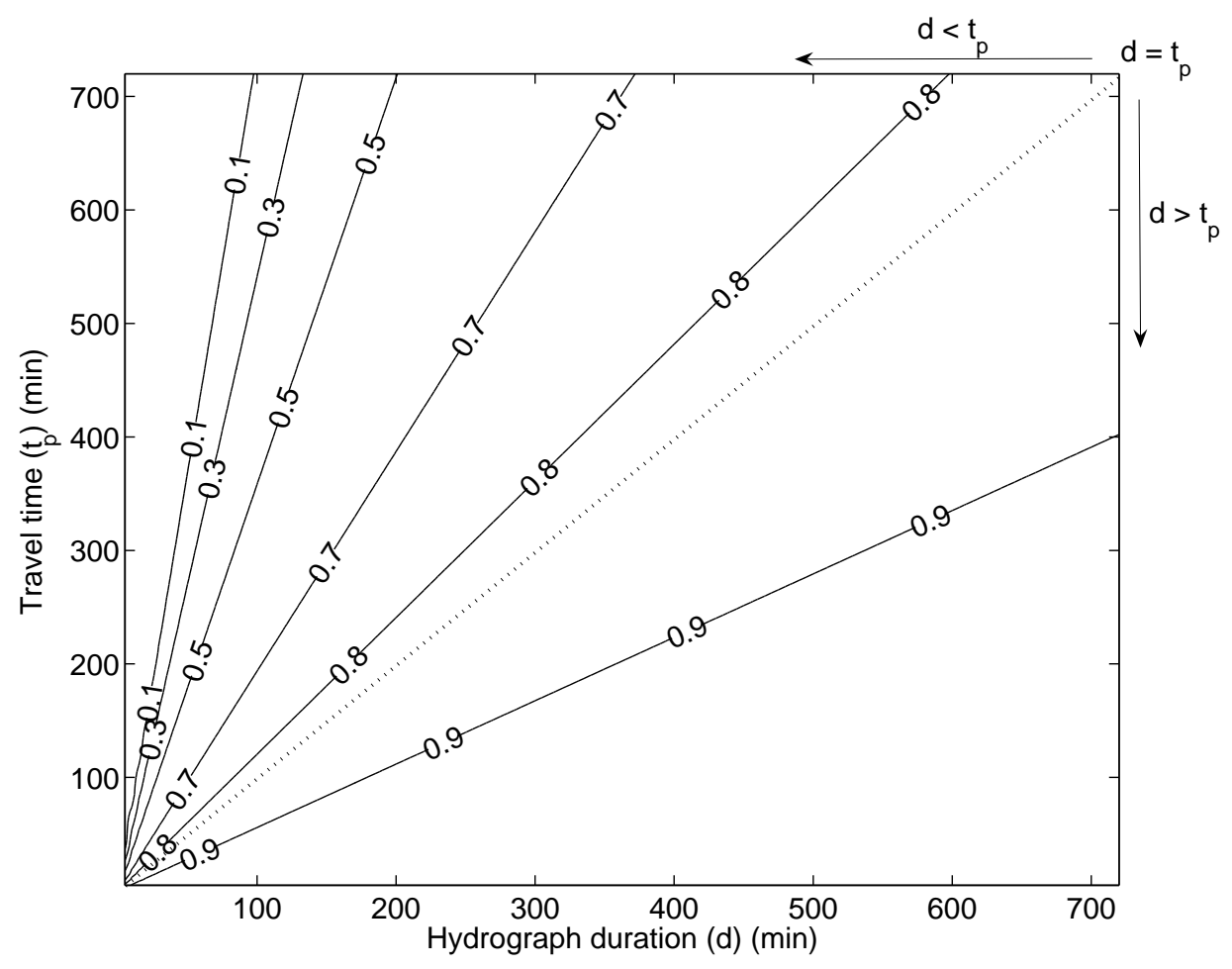

Figure 8: Attenuation $\left(Q_{o u t} / Q_{i n}\right)$ as a function of $t_{p}$ and $d$. 
However, this conclusion can change when considering source control: even if, without source control, attenuation is not relevant, flow in the sewer system is not far from conditions where attenuation can become significant $\left(t_{p}>d\right)$. This suggests that even relatively small modifications in hydrograph shapes can make attenuation a relevant process.

\subsection{Flow-rate attenuation and source control regula- tions}

Most common regulations are of two kinds (Petrucci et al. 2013): those requiring developers to limit runoff flow-rate downstream of each new urbanization, and those limiting runoff volume. Flow-rate regulations, more common in practices, fix a maximum specific flow-rate for urban areas $\left(q^{*}\right.$, in $\left.\mathrm{L} \mathrm{s}^{-1} \mathrm{ha}^{-1}\right)$ for a given design storm. In some cases (e.g. in most French local regulations) $q^{*}$ is fixed, while in other (e.g. in most US local regulations) it is given as a function of "predevelopment flow-rate", to be calculated for each application. Volume regulations define a minimal specific volume $i^{*}$, usually in $\mathrm{mm}\left(1 \mathrm{~mm}=10 \mathrm{~m}^{3} \mathrm{ha}^{-1}\right)$, that has to be removed from runoff (by infiltration, evapotranspiration, etc.) upstream of the sewer system. In our analysis, we will use a simple representation of these two regulations (figure 3.2) starting from a rectangular hydrograph AppendixA of volume $V$, duration $d$ and flow-rate $Q_{\text {in }}$ :

- a flow-rate regulation reduces flow-rate from $Q_{\text {in }}$ to $q^{*} A$ ( $A$ is the impervious surface of the upstream area) without affecting the volume of the hydrograph, thus increasing its duration;

- conversely, a volume regulation reduces the volume of the hydrograph by $i^{*} A$, reducing the duration but without changing $Q_{i n}$;

According to the preceding discussion about $d$ and $t_{p}$, to reduce the contribution of an impervious area to the flow-rate at the catchment's outlet, two source control strategies are available. The first one is to directly reduce the flow-rate entering the sewer system. The second one is to take advantage of attenuation, in order that an high flow-rate entering the sewer system will be consistently reduced at the outlet.

Flow-rate regulations follow the first strategy: independently from the distance to the outlet (measured by the travel time $t_{p}$ ), flow-rate is limited. By contrast, volume regulations can take advantage of the attenuation: if it is possible to sufficiently reduce $d$ compared to $t_{p}$, any flow-rate entering the sewer will be negligible at the outlet. The effectiveness of this second strategy depends
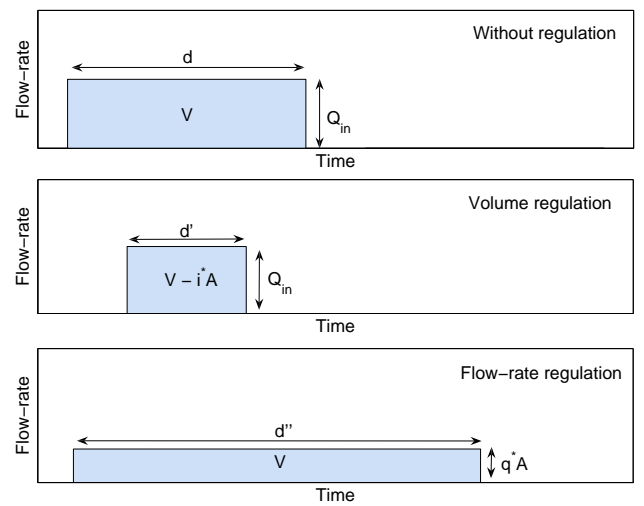

Figure 9: Schematic hydrographs corresponding to source control regulations.

on the position of the source area relatively to the outlet: if $t_{p}$ is small, the reduction in $d$ to obtain a significant attenuation will be much more considerable than if $t_{p}$ is large. In other terms, we can suppose that the second strategy (reducing $d$ through volume regulations) will be more effective when applied far from the outlet, while the first one (reducing the flow-rate entering the sewer) will be comparatively more effective close to the outlet.

In the following section, this hypothesis is tested for representative characteristics of urban catchments. Thus, we will study the contribution of a "parcel" of impervious area to the flow-rate at the catchment's outlet, as a function of the source control regulation and of the travel-time from the outlet.

\subsubsection{Hypotheses}

We consider a catchment of fixed concentration time $t_{c}=4 \mathrm{~h}$ (corresponding to a medium-sized city, or to part of a large one) and we consider a parcel of it. To define the "reference" hydrograph (i.e. without regulations), we apply the rational formula to the parcel:

$$
Q_{\text {in }}=C \cdot I \cdot A
$$

where $\mathrm{C}$ is the runoff coefficient and I the rainfall intensity. We choose an impervious surface so that $C \cdot A=$ 1 ha (e.g. a parking area of 1 ha with $C=1$, or an housing estate of 2.5 ha with $C=0.4$ ).

The relationship between $Q_{i n}$ and $V$ is not arbitrary, but is defined by rainfall. For a realistic pluviometry, we used data from a weather station $20 \mathrm{~km}$ south of Paris (Bretigny-sur-Orge). In particular we used the IDF relationship (Intensity-Duration-Frequency) in the form of the Montana formula (Chocat et al., 1997), for a return 
period of 10 years. Thus, rainfall intensity $I$ is a function of duration $d_{\text {rain }}$ depending on two parameters ( $a$ and $b$ ):

$$
I\left(d_{\text {rain }}\right)=a d_{\text {rain }}^{-b}
$$

Under this hypothesis, for each value of $d_{\text {rain }}$, the reference hydrograph is defined by:

$$
\begin{aligned}
& Q_{\text {in }}=(C A) \cdot I \\
& V=(C A) \cdot I \cdot d_{\text {rain }}=Q_{\text {in }} \cdot d_{\text {rain }}
\end{aligned}
$$

The maximum flow-rate at the outlet of the catchment $\left(Q_{\text {out }}\left(t_{p}\right)\right)$ can be calculated according to equation 12 Hydrographs modified by source control regulations are constructed following the scheme presented in figure 3.2 .

- for volume regulations, $Q_{i n}^{\prime}=Q_{i n}$, and

$$
V^{\prime}=V-i^{*} \cdot C A
$$

- for flow-rate regulations, $V^{\prime}=V$, and

$$
Q_{i n}^{\prime}=q^{*} \cdot C A
$$

The specific storage volume $v^{*}$ required to comply with the regulations can be calculated: for volume regulations, $v^{*}=i^{*}$; for flow-rate regulations, it is necessary to use a dimensioning procedure. We applied the standard method adopted in France (the so-called "rainfall method"), which is based on the Montana formula and requires only the knowledge of the IDF relationships discussed before (i.e. of the parameters $a$ and $b$ ). For different values of $q^{*}$, the resulting values of $v^{*}$ are given in table 4 .

Finally, we define the intervals of $t_{p}$ and $d_{\text {rain }}$ to be considered, according with the hypothesis on the concentration time of the catchment $(4 \mathrm{~h})$ :

- $t_{p}$ is limited to $4 \mathrm{~h}$, because for the parcels farthest from the outlet, $t_{p} \approx t_{c}$;

- under the hypothesis that rainfall events of a duration close to $t_{c}$ are the most critical for stormwater management, we can consider values of $d_{\text {rain }}$ between $\frac{1}{2} t_{c}=2 \mathrm{~h}$ and $2 t_{c}=8 \mathrm{~h}$. For each regulation and each parcel (i.e. each $t_{p}$ ), we will consider the maximum $Q_{\text {out }}\left(d_{\text {rain }}\right)$, representing the maximum contribution of that parcel to the flow-rate at the outlet, for a 10-year rainfall event having a duration close to $t_{c}$.
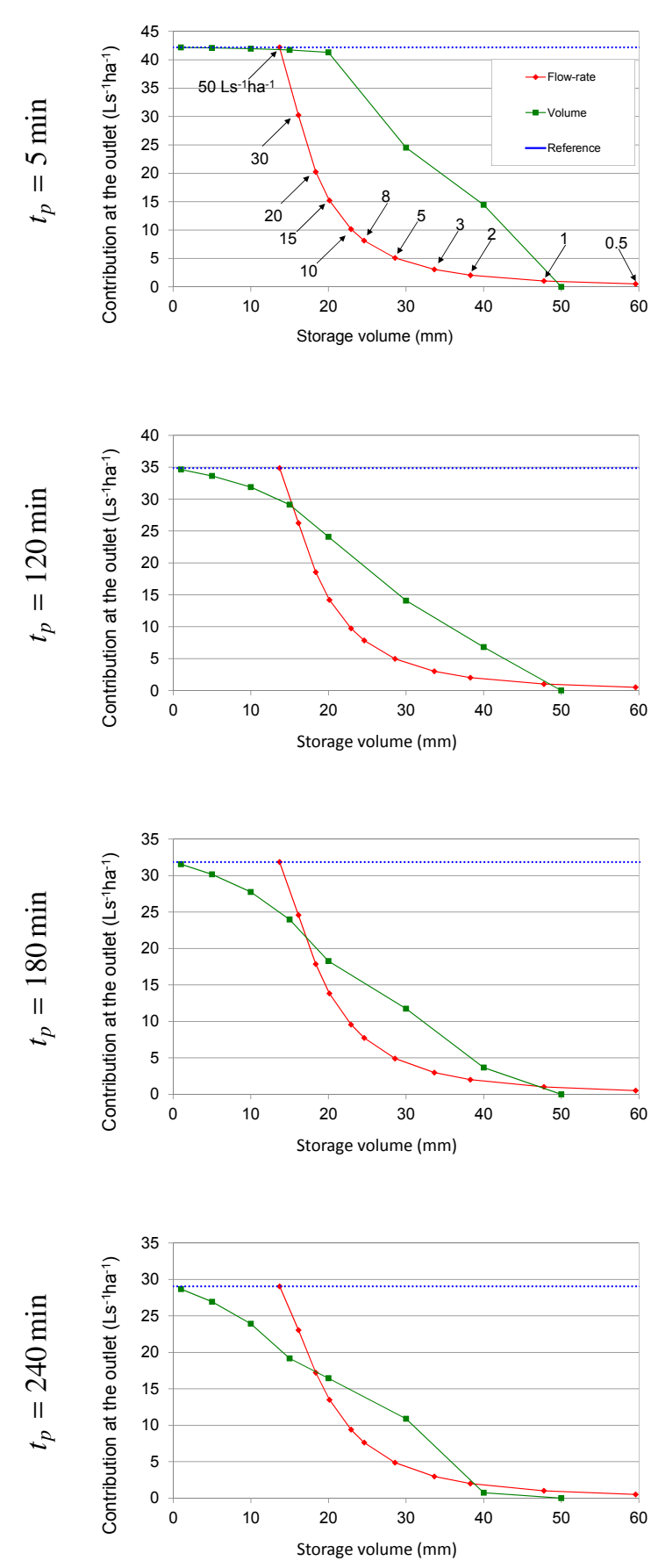

Figure 10: Effects of attenuation on source control regulations: maximum $\frac{Q_{\text {out }}}{A}$ for a 10 -year return period rain event, $d_{\text {rain }}$ between $t_{c} / 2$ (120 minutes) and $2 t_{c}$ (480 minutes). 


\begin{tabular}{rrrrrrrrrrrr}
\hline$q *\left(\mathrm{~L} \mathrm{~s}^{-1} \mathrm{ha}^{-1}\right)$ & 0.5 & 1 & 2 & 3 & 5 & 8 & 10 & 15 & 20 & 30 & 50 \\
$v *(\mathrm{~mm})$ & 59.6 & 47.8 & 38.3 & 33.6 & 28.6 & 24.6 & 22.9 & 20.1 & 18.4 & 16.1 & 13.8 \\
\hline
\end{tabular}

Table 4: Storage volumes necessary to comply with flow-rate regulations.

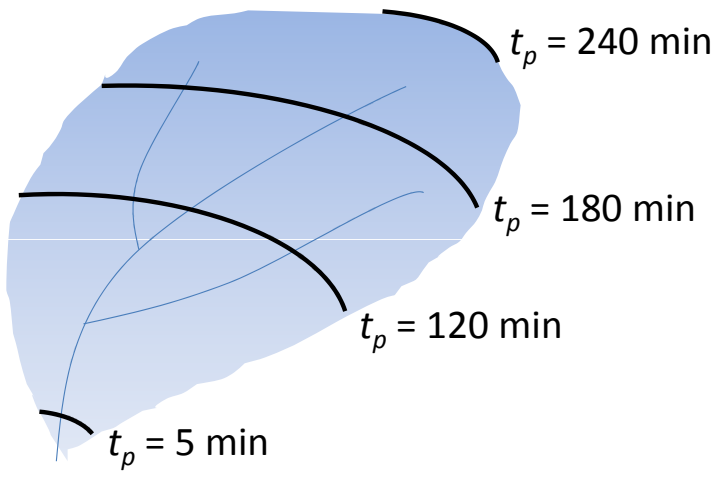

Figure 11: Schematic representation of the considered $t_{p}$ values in terms of position in the catchment.

\subsubsection{Results and discussion}

The results of this calculation, for increasing values of $t_{p}$, are presented in figure 10 . A schematic interpretation of the different values of $t_{p}$ considered in terms of position in the catchment is given in figure 11 .

A first observation concerns the attenuation of the reference flow-rate (represented by the dotted horizontal line in each graph): passing from $t_{p}=5 \mathrm{~min}$ to $t_{p}=240 \mathrm{~min}$, the reference flow-rate passes from $42 \mathrm{~L} \mathrm{~s}^{-1} \mathrm{ha}^{-1}$ to $30 \mathrm{~L} \mathrm{~s}^{-1} \mathrm{ha}^{-1}$.

Considering the plot for $t_{p}=5 \mathrm{~min}$, attenuation is negligible, and we can observe the effects of source control regulations in a "no attenuation" case. Flow-rate regulations are more effective than volume regulations (in this context, effectiveness is the ability to reduce further $Q_{\text {out }}$ with the same storage volume), with two exceptions. The first exception is when $q^{*}$ is higher than the reference flow-rate, and thus the flow-rate regulation is ineffective. The second exception is for $i^{*}=50 \mathrm{~mm}$ : in this case the volume regulation require developers to store a volume higher than the rainfall, leaving no runoff downstream.

For $t_{p}=120 \mathrm{~min}$, the impervious parcel considered is placed, in terms of $t_{p}$, in the "middle" of the catchment. Attenuation starts to be visible: while the flowrate regulation curve is mainly unchanged since the previous case, the volume regulation curve is considerably flattened. For instance, a volume of $i^{*}=40 \mathrm{~mm}$ reduces $Q_{\text {out }}$ to $5 \mathrm{~L} \mathrm{~s}^{-1} \mathrm{ha}^{-1}$, instead of $15 \mathrm{~L} \mathrm{~s}^{-1} \mathrm{ha}^{-1}$ for $t_{p}=5 \mathrm{~min}$. Even small values of $i^{*}$ (i.e. $<20 \mathrm{~mm}$ ) reduce $Q_{\text {out }}$. However, attenuation is still not enough to change the order of effectiveness between volume and flow-rate regulations.

For $t_{p}=180 \mathrm{~min}$ ("three quarters" of the way up the catchment) the effect is stronger: only the flowrate regulations between $q^{*}=2 \mathrm{~L} \mathrm{~s}^{-1} \mathrm{ha}^{-1}$ and $q^{*}=$ $20 \mathrm{~L} \mathrm{~s}^{-1} \mathrm{ha}^{-1}$ are more effective than volume ones. Furthermore, for $i^{*}=40 \mathrm{~mm}, Q_{o u t}$ is zero: without attenuation the flow-rate produced by this regulation was around $15 \mathrm{~L} \mathrm{~s}^{-1} \mathrm{ha}^{-1}$, but at this distance from the outlet attenuation makes it negligible.

At last, for the farthest impervious areas of the catchment $\left(t_{p}=240 \mathrm{~min}\right)$, flow-rate regulations are more effective than volume ones only for $2 \mathrm{~L} \mathrm{~s}^{-1} \mathrm{ha}^{-1}<q^{*} \leq$ $15 \mathrm{~L} \mathrm{~s}^{-1} \mathrm{ha}^{-1}$.

These results show that the best regulation to reduce the contribution of a parcel to the outlet flow-rate depends on the position of the parcel in the catchment. We confirmed our initial hypothesis: while flow-rate regulations do not take advantage of attenuation and are, thus, poorly influenced by the outlet distance, volume regulations grow more efficient moving away from the outlet. We also showed that the distances involved in this process are compatible with those characteristic of actual urban catchments.

To underline the practical interest of these findings, we can point out that we used, in our example, pluviometry data from the Paris region. With this data, the flow-rate regulations whose effectiveness, as compared with volume ones, is more sensitive to the position in the catchment are mainly $q^{*}=1 \mathrm{~L} \mathrm{~s}^{-1} \mathrm{ha}^{-1}$ and $q^{*}=2 \mathrm{~L} \mathrm{~s}^{-1} \mathrm{ha}^{-1}$. These values are the most usual in the (uniform) rules adopted by local authorities in this region (Petrucci et al. 2013). Hence, our results show that these rules could be replaced by non-uniform ones mixing flow-rate and volume regulations, increasing their effectiveness.

\section{Conclusions}

In this paper, we developed a model of flow attenuation in sewers, and applied it to source control regulations. The starting point was the idea that modeling processes relevant at the city-scale, i.e. at the same scale at which the regulations are elaborated, would result in models able to produce significant information 
on source control without requiring excessive (and superfluous) amounts of data. In this sense, we are testing the "pragmatical interest" of a top-down modeling approach.

The flow-rate attenuation model developed has several limits. The first is that it considers attenuation alone, and describes the fate of the hydrograph generated by a parcel without taking into account hydrograph superposition, backwater effects, etc. However, this limit is more practical than theoretical, and it does not affect the interest of the procedure as an illustration of the top-down approach.

A second limit is the extrapolation of the model from a conduit to a sequence of conduits (i.e. the drainage system). This extrapolation should be discussed and verified by further researches, and the model adapted consequently. However, we can suppose that, even if some numerical adaptation will prove necessary, the model structure and its main features will stay unchanged.

The main result of our work, beside the numerical aspects that could be reviewed by further researches, is thus in the application to source control: starting from only two types of information on the catchment (the IDF curve and the concentration time) we determined where, in the catchment, a flow-rate regulation is more effective than a volume regulation, and vice versa. This result, given in terms of travel time $t_{p}$, could be translated according to the sewer system characteristics in a stormwater zoning. A similar zoning could then be used to suggest which type of BMP is more suited for a given new development, according to its position in the catchment.

The example proposed in this paper, even if limited in scope, illustrates well the practical interest of a topdown modeling approach in urban hydrology applications. In particular, it is a promising option for the planning of "soft" stormwater management strategies that have been seldom integrated by local authorities in detailed modeling.

\section{References}

Ackers, P., Harrison, A., 1964. Attenuation of flood waves in partfull pipes. In: ICE PROCEEDINGS. Vol. 28. Thomas Telford, pp. 361-382.

Ackers, P., Harrison, A., Watkins, L., Sarjinson, E., McDowell, D., Smith, K., Hall, J., Appleby, F., Henderson, F., 1965. Discussion. Attenuation of flood waves in part-full pipes. In: ICE PROCEEDINGS. Vol. 32. Thomas Telford, pp. 608-622.

Andoh, R., Declerck, C., 1999. Source control and distributed storage - a cost effective approach to urban drainage for the new millennium? In: Proc. the Eighth International Conference on Urban Storm Drainage, Sydney, Australia. pp. 1997-2005.
Andréassian, V., 2005. Three riddles in hydrological modelling. Mémoire d'Habilitation à Diriger les Recherches soutenu à l'Université Pierre et Marie Curie le 22 avril 2005.

Azzout, Y., Barraud, S., Cres, F., 1994. Techniques alternatives en assainissement pluvial: choix, conception, réalisation et entretien. Technique \& Documentation, Lavoisier.

Balascio, C., Lucas, W., 2009. A survey of storm-water management water quality regulations in four Mid-Atlantic States. Journal of environmental management 90 (1), 1-7.

Bergstrom, S., Graham, L., 1998. On the scale problem in hydrological modelling. Journal of Hydrology 211 (1-4), 253-265.

Blöschl, G., Sivapalan, M., 1995. Scale issues in hydrological modelling: a review. Hydrological processes 9 (3-4), 251-290.

Booth, D., Jackson, C., 1997. Urbanization of aquatic systems: degradation thresholds, stormwater detection, and the limits of mitigation. Journal of the American Water Resources Association 33 (5), 1077-1090.

Chocat, B., et al., 1997. Encyclopédie de l'hydrologie urbaine et de l'assainissement. Eurydice 92, Technique \& Documentation, Lavoisier.

Chow, V., 1959. Open-channel hydraulics. McGraw-Hill.

Elliott, A., Trowsdale, S., 2007. A review of models for low impact urban stormwater drainage. Environmental Modelling and Software 22 (3), 394-405.

Faulkner, B., 1999. The control of surface water runoff from new development - UK national 'policy' in need of review? Urban Water 1 (3), 207-215.

Hayami, S., 1951. On the propagation of flood waves. BulletinsDisaster Prevention Research Institute, Kyoto University 1, 1-16.

Hingray, B., Picouet, C., Musy, A., 2009. Hydrologie: Une science pour l'ingénieur. Presses polytechniques et universitaires romandes.

Klemeš, V., 1983. Conceptualization and scale in hydrology. Journal of Hydrology 65, 1-23.

Kovacs, Y., 1988. Modèles de simulation d'écoulement transitoire en réseau d'assainissement. Ph.D. thesis, Cergrene, Ecole Nationale des Ponts et Chaussées, Paris.

Labadie, J., 2007. Automation and real-time control in urban stormwater management. In: Cities of the Future: Towards Integrated Sustainable Water and Landscape Management. IWA Publishing, London, UK, Ch. 20.

Lee, J. G., Selvakumar, A., Alvi, K., Riverson, J., Zhen, J. X., Shoemaker, L., hsiung Lai, F., 2012. A watershed-scale design optimization model for stormwater best management practices. Environmental Modelling \& Software 37, 6-18.

Mouy, N., Duguet, P., Laurent, C., 2007. Faisabilité hydraulique du zonage pluvial à Paris. In: GRAIE, Novatech 2007, Lyon, France.

Petrucci, G., Rioust, E., Deroubaix, J.-F., Tassin, B., 2013. Do stormwater source control policies deliver the right hydrologic outcomes? Journal of Hydrology. Special issue on periurban catchments. 485, 188-200.

Petrucci, G., Tassin, B., 2011. Hydrographs' attenuation in sewers. effects on stormwater source control regulation. In: 12th International Conference on Urban Drainage, Porto Alegre, Brazil, 11-16 September 2011. hal-enpc.archives-ouvertes.fr/hal-00698418. URL hal-enpc . archives - ouvertes . fr/hal-00698418

Revitt, M., Scholes, L., Ellis, B., 2008. The best management practice catalogue developed within the daywater project. In: Thevenot, D. (Ed.), Daywater: An Adaptive Decision Support System for Urban Stormwater Management. IWA Publishing. pp. 79-86.

Rossman, L., 2004. Storm Water Management Model (SWMM version 5.0) user's manual. United State Environment Protection Agency.

Rossman, L., Supply, W., 2006. Storm water management model quality assurance report: Dynamic wave flow routing. National 
Risk Management Research Laboratory, Environmental Protection Agency, Cincinnati, Ohio.

Roy, A., Wenger, S., Fletcher, T., Walsh, C., Ladson, A., Shuster, W., Thurston, H., Brown, R., 2008. Impediments and solutions to sustainable, watershed-scale urban stormwater management: Lessons from australia and the united states. Environmental Management 42, 344-359.

Schütze, M., Campisano, A., Colas, H., Schilling, W., Vanrolleghem, P. A., 2004. Real time control of urban wastewater systems - where do we stand today? Journal of Hydrology 299 (3-4), 335 - 348.

Shannon, C., 1949. Communication in the presence of noise. Proceedings of the IRE 37 (1), 10-21.

Singh, V. P., 1988. Hydrologic systems Rainfall-runoff modeling volume 1. Prentice Hall: A division of Simon \& Schuster Englewood Cliffs, New Jersey.

Sivapalan, M., Young, P. C., 2005. Downward approach to hydrological model development. In: Andersen, M. G. (Ed.), Encyclopedia of Hydrological Sciences. John Wiley \& Sons, New York, pp. 2081-2098.

Urbonas, B. R., Jones, J. E., 2001. Summary of emergent urban stormwater themes. In: Urbonas, B. R. (Ed.), Linking Stormwater BMP Designs and Performance to Receiving Water Impact Mitigation. ASCE.

Viollet, P., Chabard, J., Esposito, P., Laurence, D., 2002. Mécanique des fluides appliquée. Ecoulements Incompressibles dans les Circuits, Canaux et Rivières, autour des Structures et dans l'Environnement. Presses des Ponts et Chaussées, Paris, France.

Walsh, C., Fletcher, T., Ladson, A., 2005. Stream restoration in urban catchments through redesigning stormwater systems: looking to the catchment to save the stream. Journal of the North American Benthological Society 24 (3), 690-705.

Weinmann, P., Laurenson, E., 1979. Approximate flood routing methods: a review. Journal of the Hydraulics Division 105 (12), 15211536.

\section{AppendixA. Relevance of the hydrographs' shape}

In the model development, we considered a sinusoidal hydrograph. Even if this hypothesis is quite realistic, the use of a single hydrograph's shape can introduce a bias in the model. This bias could be corrected, for example, taking into account the "shape factor" $\alpha$ appearing in equation 2. However, before introducing an additional element in the model, increasing its complexity, we tested the relevance of a similar correction.

The test consisted in a validation of the model over simulations analogous to those used for model development, but with hydrographs other than sinusoidal $(\alpha=$ $\left.\frac{2}{\pi}\right)$. We considered three shapes: triangular $\left(\alpha=\frac{1}{2}\right)$, rectangular $(\alpha=1)$ and a gamma distribution with parameters $k=5$ and $\theta=1$. This last case corresponds to the output of a Nash cascade model of $n=k=5$ reservoirs (Singh, 1988). Hence, this choice corresponds to a realistic hydrograph's shape. In this case, $\alpha$ can not be defined in the usual way, because $d_{\text {Nash }}=\infty$. We can consider an alternative definition of $d$, for instance considering the time at which $95 \%$ of the hydrograph volume has flowed. According to this definition, $\alpha=0.44$.

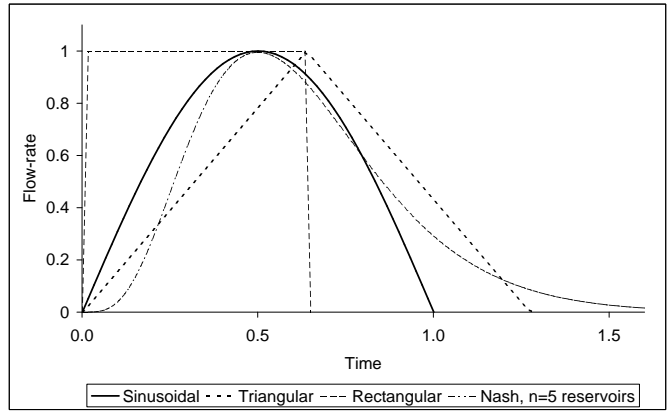

Figure A.12: Normalized shapes of the tested hydrographs

The hydrographs tested, normalized and compared to the sinusoidal one, are plotted in figure A.12

We performed $N=3000$ simulations for each hydrograph shape. Results in terms of $M S E$ obtained for each model and hydrograph's shape are given in table A.5. As an example, figure A.13 shows the results of the complete Ackers' model for the three hydrograph's shapes.

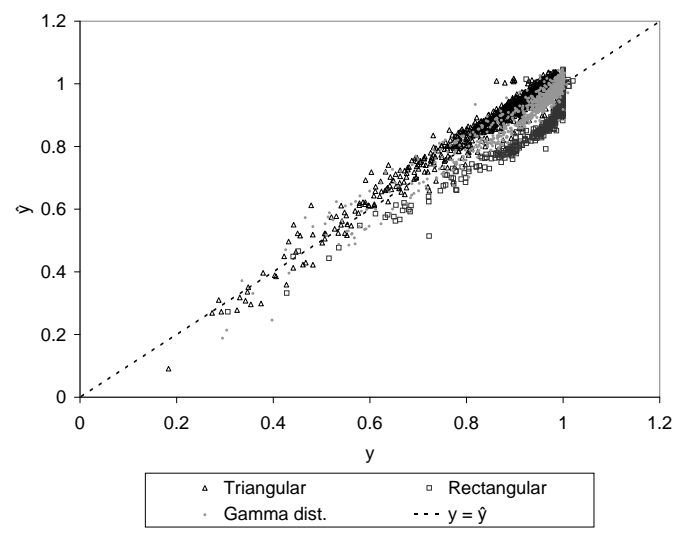

Figure A.13: Validation of the complete Ackers model

Passing from calibration (table 3) to validation (table A.5, we observe a degradation of model accuracy, as can be expected. This degradation is particularly strong for the rectangular shape. Figure A.13 shows that, for this shape, the attenuation estimated by the model is generally smaller than that simulated. A potential explanation of this phenomenon is that the strong discontinuities presented by rectangular hydrographs cause a stronger attenuation than "smoother" shapes. In fact, better performance is obtained with the gamma dis- 


\begin{tabular}{lccc} 
Model & Triangular & Rectangular & Gamma distribution \\
\hline Ack. comp. & $9.27 \times 10^{-4}$ & $2.06 \times 10^{-3}$ & $5.15 \times 10^{-4}$ \\
Ack. simp. & $5.27 \times 10^{-4}$ & $2.56 \times 10^{-3}$ & $5.16 \times 10^{-4}$ \\
Add. comp. & $1.37 \times 10^{-3}$ & $1.43 \times 10^{-3}$ & $4.49 \times 10^{-4}$ \\
Add. simp. & $1.22 \times 10^{-3}$ & $1.73 \times 10^{-3}$ & $5.21 \times 10^{-4}$
\end{tabular}

Table A.5: Results of the validation (MSE, $N=3000$ ).

tribution, i.e. the more realistic and smooth hydrograph.

In general, the degradation in the model performances is always smaller than a factor of 10 in terms of $M S E$, even for rectangular hydrographs. The good performance for the most realistic hydrographs indicates that the model is applicable outside of the calibration domain, and the sinusoidal hydrographs hypothesis is acceptable.

\section{AppendixB. Simulation procedure}

The algorithm used to realize the $N$ simulations of the flow model is the following:

1. initialization: $j=0$;

2. extraction of the values $l, D, s, n$ for the pipe, from a uniform distribution between the ranges of table 1 . $k=1$;

3. calculation of $v_{f}$. If $v_{f}$ is out of the range of table 1 go back to (2). Calculation of $Q_{f}, F_{f}, V_{c}$;

4. extraction of $Q_{0}$ in the range $\left(0 \mathrm{~m}^{3} / \mathrm{s} ; 0.9 \cdot Q_{f}\right)$;

5. extraction of $V$ in the range $\left(0 \mathrm{~m}^{3} ; k \cdot V_{c}\right)$, with $k=$ $\{1, \ldots, 10\}$

6. extraction of $Q_{i n}$ in the range $\left(0.001 \mathrm{~m}^{3} / \mathrm{s} ; Q_{f}-Q_{0}\right)$;

7. calculation of $d$. If $d<2 \mathrm{~min}$ or $d>24 \mathrm{~h}$, go back to $(5)$;

8. flow simulation using SWMM 5 applied to the single pipe;

9. if $\left(V_{\text {in }}-V_{\text {out }}\right) / V_{\text {in }}<0.01$, back to (2);

10. calculation of $Q_{\text {out }}$;

11. recording of the results. $j=j+1 . k=k+1$;

12. if $k<11$ back to (4);

13. if $j<N$ back to (2); else, end of the procedure.

The algorithm include several verifications on the admitted values of the variables:

- $v_{f}$ (step 3) must be included in the ranges of table 1, representing current practices for sewer design;

- the upper limits on $Q_{0}$ and $Q_{\text {in }}$ (steps (4) et (6)) are to avoid the pipe being surcharged or pressurized;
- the lower limit on $Q_{\text {in }}\left(11 \mathrm{~s}^{-1}\right.$, step (6)) is to avoid simulations of negligible peak flow-rates;

- the upper limit on $V$, depending on $V_{c}$ and a varying factor $k$ (step (5)) allows the algorithm to explore a wide range of hydrographs, according to the pipe's size;

- the lower limit on $d$ (2 min, step (7)) is a consequence of the Nyquist-Shannon theorem (Shannon, 1949), linking a signal's period to the sampling frequency necessary to describe it. The smallest sampling frequency of the entering hydrograph admitted by the simulation code is of $1 \mathrm{~min}^{-1}$, allowing a minimal period of $T \geq 2 \mathrm{~min}$;

- the upper limit on $d$ (step (7)) is to avoid that the peak flow-rate reach the outlet after the end of the simulation. 